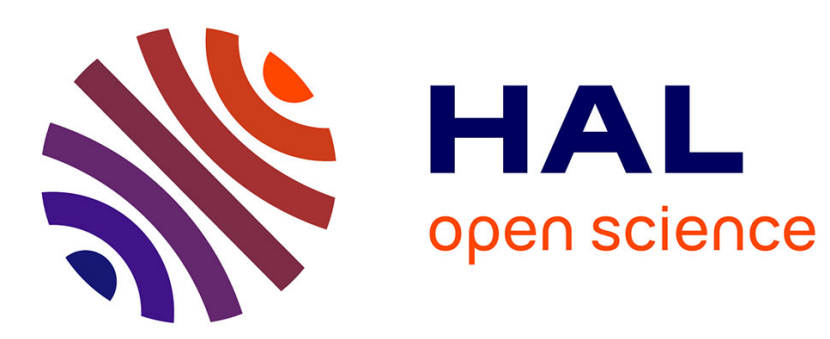

\title{
Positive Mood and the Perception of Variability Within and Between Groups
}

\author{
Steven J. Stroessner, Diane M. Mackie, Venezia Michalsen
}

\section{To cite this version:}

Steven J. Stroessner, Diane M. Mackie, Venezia Michalsen. Positive Mood and the Perception of Variability Within and Between Groups. Group Processes and Intergroup Relations, 2005, 8 (1), pp.5-25. 10.1177/1368430205048619 . hal-00571594

\section{HAL Id: hal-00571594 https://hal.science/hal-00571594}

Submitted on 1 Mar 2011

HAL is a multi-disciplinary open access archive for the deposit and dissemination of scientific research documents, whether they are published or not. The documents may come from teaching and research institutions in France or abroad, or from public or private research centers.
L'archive ouverte pluridisciplinaire HAL, est destinée au dépôt et à la diffusion de documents scientifiques de niveau recherche, publiés ou non, émanant des établissements d'enseignement et de recherche français ou étrangers, des laboratoires publics ou privés. 


\title{
Positive Mood and the Perception of Variability Within and Between Groups
}

\author{
Steven J. Stroessner \\ Barnard College, Columbia University \\ Diane M. Mackie \\ University of California, Santa Barbara \\ Venezia Michalsen \\ CUNY, The Graduate Center
}

\begin{abstract}
Three experiments investigated the effects of positive mood on perceptions of variability within and between groups. Participants formed impressions of two different and highly variable groups under a neutral or positive mood. When participants expected to learn about both groups, positive mood increased perceived intergroup similarity but did not affect perceived intragroup variability. In contrast, when participants expected to learn about only one group, judgments of intergroup and intragroup similarity were both affected by mood. Mood and the intergroup context influenced the nature and degree of information processing and resultant judgments of variability in social groups.
\end{abstract}

KEYWORDS group differentiation, homogeneity, mood, variability

TRANSIEnT mood states can have a profound impact both on what (e.g. Berkowitz, 1993; Mayer, Gaschke, Braverman, \& Evans, 1992; Schwarz \& Clore, 1996) and how (e.g. Ashby, Isen, \& Turken, 1999; Bless, Schwarz, \& Kemmelmeier, 1996; Ellis \& Ashbrook, 1988; Schwarz \& Clore, 1996; Worth \& Mackie, 1987) people think. Although typically ephemeral, moods have been shown to influence a broad array of important mental phenomena such as judgments of risk (Leith \& Baumeister, 1996), estimates of life satisfaction (Schwarz \& Clore,
1996), and decisions about prosocial behavior (Isen, 1987). Moreover, judgments and actions can be influenced by incidental affect (Bodenhausen, 1993), moods that arise from a trivial event unrelated to the judgment at hand. Good

\section{Author's note}

Correspondence should be addressed to Steven J. Stroessner, Department of Psychology,

Barnard College, 3009 Broadway, New York, NY 10027-6598 [email: ss233@columbia.edu] 
weather, receiving a candy bar, or watching a segment of a comedy television show can influence information processing about situations, the self, and others.

Given the central role of information processing in stereotyping (see Hamilton \& Sherman, 1994), it is not surprising that moods have also been shown to impact judgments of groups and their members (Bodenhausen, Mussweiler, Gabriel, \& Moreno, 2001; Mackie \& Hamilton, 1993; Park \& Banaji, 2000). However, in contrast to earlier speculations that positive affect during intergroup encounters might lead to improved relations (e.g. Allport, 1954; Amir, 1969; Brewer \& Miller, 1984) or favorable judgments (e.g. Bower, 1991; Forgas, 1995), positive moods have under some circumstances produced unfavorable and negative judgments of groups. Positive moods have been shown to increase use of stereotypes (Bless, Schwarz \& Kemmelmeier, 1996; Bless \& Fiedler, 1995; Forgas \& Fiedler, 1996; Stroessner \& Mackie, 1992), particularly in the absence of cues suggesting that stereotype use should be avoided (Bodenhausen, Kramer, \& Süsser, 1994; Krauth-Gruber \& Ric, 2000).

The reason why stereotyping increases under positive mood has been a matter of some debate. Some theories link positive moods to stereotyping through decreases in deliberative processing; when systematic processing is difficult or unpalatable, stereotypes serve as readily available heuristics to guide judgment and behavior. According to these views, positive moods tend to diminish the willingness to thoroughly evaluate available information for a number of reasons. One account (Isen, 1987; Wegener, Petty, \& Smith, 1995) attributes decreased deliberative processing to a motivation to maintain positive mood. A second account (Schwarz, 1990; Schwarz \& Clore, 1996) suggests that positive mood indicates that the environment is secure and nonthreatening, signaling that deliberative processing is unnecessary. Both accounts also allow for the possibility of greater systematic processing (and, presumably, reduced stereotyping) under some conditions. Deliberative processing under positive mood might occur if available information is interesting or enjoyable to process (Isen, 1993), is highly discrepant with expectations (suggesting that reliance on a stereotype is inappropriate) (Krauth-Gruber \& Ric, 2000), or when accountability for judgments is increased (Bodenhausen et al., 1994). In the absence of these factors, however, systematic processing of available information is reduced when people are in a happy mood, increasing the use of available stereotypes (Bless, Bohner, Schwarz, \& Strack, 1990; Bless, Mackie, \& Schwarz, 1992; Mackie, \& Worth, 1989; Melton, 1995; Sinclair \& Mark, 1995).

Given that positive mood tends to increase reliance on stereotypes, one interesting question regards how positive mood might impact the processing of information about novel groups for which no stereotype is available. Since no stereotype is available in these situations to guide impression formation, one might expect that positive moods might actually increase deliberative processing. In fact, there is evidence that positive moods might serve to increase processing regarding novel groups. Positive affect has been shown to enhance cognitive flexibility and creativity, particularly on tasks that are enjoyable (Isen, 1993). Happy individuals show enhanced verbal fluency on a creative uses test (Phillips, Bull, Adams, \& Fraser, 2002), generate more unusual associations (Isen, Johnson, Mertz, \& Robinson, 1985), and demonstrate greater flexibility in adopting new rules in information processing (Dreisbach \& Goschke, 2004) than individuals in a neutral mood. Murray, Sujan, Hirt, and Sujan (1990), for example, showed that happy individuals were better able to generate both similarities and differences when comparing TV shows and their characters, depending on the task requirements. These studies suggest that in the absence of pre-existing stereotypes, happy individuals might show deliberative processing of information about novel groups.

Other studies, however, suggest that happy individuals' deficits in processing are not restricted to domains in which heuristics such as stereotypes are available. Several studies suggest that happiness can undermine effective functioning of executive control (Spies, Hesse, 
\& Hummitzsch, 1996), leading to increased distractibility (Dreisbach \& Goschke, 2004) and poor performance on demanding cognitive tasks (Phillips et al., 2002). These effects are particularly prounounced on tasks that are not seen as enjoyable (Isen, 1999; Phillips et al., 2002). Within social cognition, people in a positive mood do not appear to differentially attend to and weight infrequent, distinctive, or extreme information compared with people in a neutral mood (Blessum, Lord, \& Sia, 1998; Isen \& Daubman, 1984; Isen, Niedenthal, \& Cantor, 1992; Stroessner, Hamilton, \& Mackie, 1992, Experiment 2; Stroessner \& Mackie, 1992). For example, happy individuals have been shown to judge a group of diverse individuals to be as homogeneous as a group with low diversity (Queller, Mackie, \& Stroessner, 1996; Stroessner \& Mackie, 1992, 1993) and they recalled items reflecting relatively low behavioral variability (Stroessner \& Mackie, 1992, Experiment 2). These results suggest that good mood can decrease deliberative processing of information about novel groups, increasing perceived homogeneity and thereby undermining one of the potential benefits of intergroup contact (Linville, Salovey, \& Fischer, 1986; Quattrone, 1986; Wilder, 1986).

In sum, the literature suggests that positive mood produces effects that depend on the nature of the task and the attitude of the perceiver. Happiness tends to increase creativity and flexibility in thinking, but at the cost of persistence and deliberation. On tasks that require flexibility, positive mood will appear to convey an advantage, whereas the opposite will be true on tasks that require focus and deliberation. Moreover, even the negative consequences of positive mood can be attenuated when individuals are highly motivated to engage in deliberative processing, such as when the task is seen as pleasant and enjoyable. Most evidence to date, however, shows that positive moods detrimentally affect perceptions of novel groups, suggesting that perceivers generally do not experience forming impressions of novel groups as inherently enjoyable.

\section{Possible positive consequences of positive affect for intergroup perception}

Given the varied effects of mood on information processing, it is possible that positive affect might simultaneously produce both beneficial and detrimental consequences on different aspects of group judgments. In reviewing their research showing that happy individuals failed to recognize within-group variability, Stroessner and Mackie (1993; see also Mackie, Queller, Stroessner, \& Hamilton, 1996) suggested that the processes that produce a failure to differentiate within groups, while harming intragroup perception, might benefit intergroup perception. Although positive mood decreases recognition of variability within a single group, the reduced recognition of difference might be desirable when individuals are forming impressions of multiple groups or are comparing an outgroup with an ingroup. Positive mood might decrease the recognition of distinctions between members of different groups, possibly producing the perception of high intergroup similarity.

Although the effect of mood on simultaneous judgments of similarity within and between novel groups has not been examined, there exists some indirect support in the literature for the notion that positive mood might increase perceived similarity between groups. In one study (Dovidio, Gaertner, Isen, \& Lowrance, 1995), perceivers' affective states were manipulated to assess the impact on the salience of group boundaries. Specifically, participants were either given a candy bar to induce a positive mood or experienced no mood manipulation and were then asked to view a videotape of several members of an outgroup with whom their group would later interact. After viewing the videotape, participants judged whether during their upcoming interaction they thought they would feel like members of a single, superordinate group or whether they would feel like members of two separate groups. Participants in a positive mood were more likely to anticipate that they would view the aggregate as a single group and less as 
two distinct groups than did participants who had not undergone the mood induction.

Although this finding supports the prediction of reduced group differentiation by individuals in a positive mood, there remain some ambiguities and unresolved questions. First, participants in the Dovidio et al. (1995) experiment did not directly judge the similarity of the outgroup to their own group. Instead, participants indicated whether they would expect to view the members of the other group as belonging to a single, superordinate group during some future interaction. Although judgments of expected inclusiveness and similarity might correlate, they are theoretically distinguishable and might be differently impacted by other variables. Second, the targets in the Dovidio et al. study were purportedly members of an outgroup. Perceptions of outgroup members have been shown to be affected by a number of motivational variables, suggesting that the obtained results might have arisen from motivational factors to reduce or increase intergroup differentiation independent of thoroughness of processing issues (Forgas \& Fiedler, 1996; Forgas \& Moylan, 1991). Third, it is also unclear whether the effects reflect the impact of positive mood, per se, or emerged because participants in the positive mood condition underwent an experimental manipulation whereas the other participants did not. It is possible that this manipulation might have had a number of consequences in addition to altering mood. For example, the experimental manipulation might have distracted participants in the positive mood condition or led participants to be generous and inclusive in exchange for the gift.

Fourth, and most crucial in our view, it would be desirable to assess within a single experiment the simultaneous impact of positive mood on perceptions of both within- and betweengroup variability. To date, one set of studies has shown that positive mood decreased the perceived variability within a single group and another study has shown decreased intergroup differentiation between two groups. What remains unclear is the impact of positive mood on both perceptions when multiple groups are judged. Given the importance of both intragroup variability and between-group differences for differentiation and, ultimately, for intergroup relations (Campbell, 1956; Ford \& Stangor, 1992; Jetten, Spears, \& Manstead, 1998; Krueger \& Rothbart, 1990; Rothbart, Davis-Stitt, \& Hill, 1997), it is important to examine simultaneously the impact of positive mood on the perception of differentiation both within and between groups. To our knowledge, no study yet has done so.

\section{Experiment 1}

The primary goal of Experiment 1 was to examine the effects of positive mood on the perception of variability within and between novel groups. Before learning about two groups, participants experienced a manipulation designed to induce a positive or a neutral mood. Therefore, the two conditions differed only in the affective implications of the mood manipulation and not in whether participants experienced a manipulation of mood. Moreover, because the participants were members of neither group, no motivational factors to distinguish or diminish the perceived difference between ingroups and outgroups should have been activated.

Following the mood induction, participants were presented with information describing groups that were clearly distinct from one another (i.e. the groups were on average very different) but also contained a high degree of within-group variability (i.e. the groups were very heterogeneous). Participants judged the similarity of the group members to one another and the degree that the groups were similar to each other.

Based on the reduced recognition and processing of atypical or distinctive information by individuals in a positive mood, we predicted that positive mood should lead to reduced perceptions of intragroup variability as has been reported in previous studies (Queller et al., 1996; Stroessner \& Mackie, 1992, 1993). It was also expected that individuals in a good mood would see the two groups as more similar to one another than would individuals in a neutral 
mood. Why would positive mood increase rather than decrease perceived intergroup similarity? Because the groups were very different from one another, we expected that the less deliberative processing typically associated with positive mood would make recognition of those differences more difficult. Moreover, because the groups were novel, there would be no general knowledge structures (i.e. stereotypes or expectancies) suggesting that the groups would be highly dissimilar. Individuals in a positive mood therefore would be less likely to detect substantial real group differences than would individuals in a neutral mood. If these results emerged, this would suggest that positive mood might simultaneously harm (by reducing intragroup differentiation) and help (by reducing intergroup differentiation) perceptions of groups.

\section{Method}

Participants A total of 67 undergraduates enrolled in an introductory psychology course participated in the experiment in exchange for partial course credit. Participants were randomly assigned in groups of two to eight to one of the eight conditions created by crossing the mood (good vs. neutral), group order (Group A first vs. Group B first), and mood stimulus order (order 1 vs. order 2 ) variables.

\section{Stimulus materials}

Behavioral sentences A pilot test was conducted to create descriptions of two groups that differed in valence but also showed a high degree of within-group variability. Students $(N$ =24) rated a total of 32 behavioral sentences in terms of the desirability of the behavior described $(1=$ not at all desirable, $9=$ very desirable). Based on these ratings, two sets of stimulus sentences were created. A set of 12 sentences was selected to describe the behaviors of members of a hypothetical group of people labeled Group A, and 12 sentences described the members of Group B. Both the Group A $(S D=1.6)$ and Group B sets $(S D=1.6)$ reflected an identically high degree of within-group variability. ${ }^{1}$ However, the central tendency of the two groups differed. Whereas the members of
Group A typically performed desirable, friendly behaviors $(M=6.0)$, the members of Group B acted in an undesirable, unfriendly manner $(M$ $=4.0$ ). So, for example, a member of Group A might have 'planned the company picnic' or 'bought a present for a friend who was feeling depressed'. A member of Group B, however, might have 'stolen valuables from a client' or 'bought her sister a dress that didn't fit so that she could borrow it'.

Mood-inducing video excerpts To ensure that participants were in the same mood when processing information about both groups, two different video excerpts were selected for use in each mood condition. The excerpts designed to induce a positive mood showed two different comics, each performing a stand-up routine. The neutral mood videos showed these same comics, but one was acting in a serious movie scene and the other was being interviewed for a television special. Pilot testing $(N=50)$, in which students viewed only one of several prospective excerpts and then rated their mood ( 1 = sad, 9 = happy), indicated that mood ratings were higher following the two selected positive-mood excerpts $(M \mathrm{~s}=7.1$ and 7.3) than following the two selected neutral-mood excerpts $(M \mathrm{~s}=5.4$ and 5.2). Mood ratings following the two excerpts within each condition did not differ significantly (both $F \mathrm{~s}<1$ ).

Procedure Student participants were welcomed by one of two experimenters and were told that they would participate in two different studies. The first study, participants were told, was actually a pretest for a future experiment. They were to watch two short (approximately 5 min) video excerpts that would be used in a future study and were to answer several questions designed to assess their reactions. Participants were also told that because the experimenters were concerned about their seeing two excerpts in a row, the excerpts would be separated by the first half of the second study. After the first half of the second study was completed, they then would view the second clip and would finally complete the second half of the second study. This procedure was used to 
ensure that participants were in the intended mood while reading about both groups. The video order was counterbalanced to minimize the likelihood that judgments of a group could be explained in terms of viewing a specific video excerpt.

Participants were then shown one of the excerpts designed to induce either a positive (i.e. happy) or a neutral mood. After viewing this excerpt, participants completed a questionnaire containing several questions regarding their responses to the video. Embedded among these questions were two items designed to assess the effectiveness of the mood manipulation. The items were 'How did the video make you feel?' and 'How do you feel right now?' ( 1 = sad, 9 = happy).

The participants were then told that they would 'read about some behaviors that were performed by the members of a group' and that they would 'later be asked some questions that involved making some judgments about the group'. Each group member who performed a behavior, participants were told, was to be identified by her first name, and each group member performed only one behavior. Booklets containing descriptions of behaviors performed by the members of either Group A or Group B were then distributed (group order was counterbalanced). There was a single behavioral description on each page, and the descriptions appeared in a different random order in each booklet. The experimenter paced the participants through the booklets, allowing six seconds per page. After the booklets were collected, participants were given a sheet containing numerous questions about the group. We included a number of questions designed to obscure our focus on perceived variability, including questions about the perceived friendliness and intelligence of the groups' members, the likeability of the groups, and the similarity of the group to the self. Embedded in these items was one of the primary dependent measures in the study, 'How similar are the members of this group to one another?' (1 = not at all similar, $9=$ very similar $)$. The procedure was then repeated using the video clip and group behavioral descriptions that had not yet been used. After these counterbalancing procedures were completed, participants had undergone two mood manipulations designed to induce the same mood state and had read about and judged the variability within both groups.

Participants then completed a final questionnaire designed to assess perceptions of intergroup similarity. This questionnaire contained filler items and a series of questions about group differences. Three of the items asked about the degree to which the two groups were similar ('How similar (in general, in intelligence, in friendliness) are members of Group A to members of Group B?' (9 = very similar)). Because of Murray et al.'s (1990) finding that happy individuals are more likely to detect both similarities and differences between stimuli, participants were asked three similar questions phrased in terms of differences ('How different (in general, in intelligence, in friendliness) are members of Group A from members of Group B?' $(9$ = very different $)$ ). After their last group judgment, participants were again asked to report their mood ('How do you feel right now?' $(9=$ happy $))$.

\section{Results and discussion}

Effectiveness of mood manipulations Responses to the mood manipulation checks were analyzed to assess whether the video clips successfully induced the intended moods. As responses to the two manipulation check items were highly correlated for both the first and second mood inductions $(r s=.75$ and .71 , respectively), these items were averaged to create two mood indexes. The scores were then entered in a 2 (Mood) $\times 2$ (Induction) analysis of variance (ANOVA) with repeated measures on the second factor. (Preliminary analyses indicated that video order and group order variables qualified none of the obtained effects.) This analysis yielded a significant Mood effect $(F(1,65)=33.21, p<.001)$, indicating that participants reported being happier if they viewed the positive mood videos $(M=$ $6.8)$ than if they viewed the neutral mood videos $(M=5.5)$. The analysis also yielded a significant Mood $\times$ Induction interaction $(F(1$, 
Table 1. Mean variability judgments as a function of mood: Experiment 1

\begin{tabular}{lcc}
\hline & & Mood \\
\cline { 2 - 3 } Judgment & Neutral & Positive \\
\hline Between-group differentiation & & 4.3 \\
$\quad$ General similarity & 3.0 & 4.4 \\
Friendliness similarity & 4.9 & 5.1 \\
Intelligence similarity & & 5.4 \\
General difference & 6.6 & 5.6 \\
Friendliness difference & 4.8 & 4.8 \\
Intelligence difference & & 5.4 \\
Within-group similarity & 5.4 & 5 \\
\hline
\end{tabular}

$65)=5.25, p<.05)$. Separate analyses for the first and second mood inductions indicated that the first mood induction was highly successful $(M s=7.2$ vs. 5.2 for the happy and neutral conditions, respectively) $(F(1,65)=$ $43.95, p<.001)$. The second mood induction, although successful, was less powerful $(M \mathrm{~s}=6.5$ vs. 5.7, respectively) $(F(1,65)=4.97, p<.05)$. Therefore, the desired mood states were successfully induced by both manipulations.

Analysis of the last mood manipulation check indicated that participants' moods in the neutral $(M=5.5)$ and happy $(M=5.5)$ conditions did not differ at the end of the experiment.

\section{Effects of mood on perceptions of variability} Within-group similarity Responses to the item assessing perceived within-group similarity were submitted to a 2 (Mood) $\times 2$ (Group: Group A vs. Group B) ANOVA with repeated measures on the second variable. This analysis yielded only a Group main effect $(F(1,65)=6.53, p<$ $.05)$, indicating that the members of Group B $(M=5.8)$ were seen as more similar to one another than the members of Group A $(M=$ $5.0)$. As reflected in the equal means displayed at the bottom of Table 1, the Mood main effect was not significant $(F<1)$. Surprisingly, mood effects on perceived variability within groups were attenuated in this multiple group context.
Between-group differentiation Responses to the questions assessing group differences were analyzed separately, and mean responses are displayed in Table 1. Responses to the items about the general similarities and differences between the groups both yielded significant effects of mood. Individuals in a positive mood perceived the groups as more similar $(F(1,65)$ $=7.89, p<.01)$, and less different $(F(1,65)=$ $6.33, p<.05)$, than did individuals in a neutral mood. The items focusing on differences and similarities in friendliness yielded similar effects. Happy participants reported viewing the groups as more similar $(F(1,65)=6.63, p<$ $.05)$, and less different $(F(1,65)=5.09, p<.05)$, than did participants in a neutral mood. Interestingly, analyses of the items regarding differentiation in intelligence produced no significant effects (both $p \mathrm{~s}>.40$ ). Positive mood therefore appeared to decrease perceived intergroup differentiation, but this occurred particularly on traits relevant to the behavior of group members.

The results of Experiment 1 extend our understanding of mood effects on group perception in several respects. Participants in a good mood judged the members of the two groups displaying real and pronounced group differences as more similar (and less different) than did participants in a neutral mood. Because making distinctions between groups 
has been shown to produce ingroup bias and discrimination against outgroups (see Brewer, 1979; Turner, 1991), this finding suggests that positive mood might have some beneficial consequences for intergroup interactions.

Contrary to predictions and previous findings, however, judgments of the variability within the groups were unaffected by mood. Participants in both a good and neutral mood saw the groups as being equally (and highly) similar, with both means above the scale midpoint of 5. These findings suggest that the recognition of diversity was poor in general, even by those individuals in a neutral mood.

One possible reason for this failure of participants to detect the high degree of intragroup variability might relate to the multigroup context of the study. Individuals in earlier studies on mood and group impression formation received information describing the members of a single social group. In the present experiments, however, individuals expected to form impressions of two different groups and indeed did so. Because perceivers expected to read about two groups, it is possible that they might not have seen the detection of within-group differences as crucial to the task at hand. If that were the case, individuals might have focused on detecting differences between the groups rather than variations within groups.

This possibility is consistent with the literature on context effects on social judgment (Eiser, 1971; Krueger \& Rothbart, 1990; Krueger, Rothbart, \& Sriram, 1989; Tajfel \& Wilkes, 1963; Wilder \& Thompson, 1988). In one classic experiment, Doise, Deschamps, and Meyer (1978) asked participants to make trait ratings of group members. Some participants expected to rate members of only one group (although they completed ratings of both groups), whereas the other participants expected to rate members of two different groups. Participants who expected two groups showed assimilation in their ratings of each groups' members and contrast between members of different groups. Thus, the knowledge that one will receive information about more than one group appears to minimize intragroup differentiation, presumably because processing goals vary in single group versus multiple group contexts. In the former case, the perceiver tends to process information describing group members with a goal or inferring what group members are like 'on average' (i.e. the central tendency) and how they differ from one another (i.e. intragroup variability). In the latter case, perceivers appear less inclined to focus on detecting variability within either group, given that they might process the information with the implicit goal of making between-group comparisons. Although the degree of overlap in the distributions of different groups has been shown to affect judgments (Ford \& Stangor, 1992), it is not clear that people appreciate the impact of variability information (cf. Linville et al., 1986) and, consequently, they may be less inclined to focus on abstracting variability information when they receive information about more than one group. If so, this might attenuate mood effects on perceived variability within groups, as was found in Experiment 1.

This interpretation is speculative because expectations about the number of groups that would be encountered were not systematically varied in our first experiment. Participants had been forewarned that they would be reading about two groups, so the effects of the expectancy variable can only be inferred from comparisons with previous experiments in which information about only one group was presented. A second experiment therefore was conducted in which participants' expectancies regarding the number of groups they expected to learn about was manipulated. We hypothesized that the impact of mood on judgments of within group similarity would depend on the expected number of target groups. When participants expected to form impressions of two groups, we expected to replicate the findings of Experiment 1. In contrast, when participants expected to form an impression of only one group, it was expected that people in a neutral mood should better detect the low similarity of the members of a highly variable group, although this effect should apply only to the first group encountered. Predictions for the second group were more speculative, given the 
possible changes in processing goals as a function of introducing a multiple-group context in the middle of the study. If information describing a second group was presented after participants had been led to believe that only one group would be described, they might then change their information processing strategy to detect betweengroup differences.

\section{Experiment 2}

Experiment 2 was conducted with several goals in mind. One goal was to replicate the finding that positive mood reduces intergroup differentiation. A second goal was to test the interpretation that mood effects did not emerge on perceived intragroup variability in Experiment 1 because of the multigroup context. To test this hypothesis, participants in Experiment 2 were led to believe either that they would form an impression of one group or of two groups. A third goal was to collect a measure that might shed light on the basis of the obtained effects. We focused on participant's free recall of presented behavioral descriptions as a reflection of the degree of deliberative processing. Accordingly, we expected that participants in a neutral mood would recall more items than would participants in a positive mood.

\section{Method}

Participants A total of 118 undergraduates recruited from the introductory psychology pool were recruited for participation in exchange for partial course credit. Participants were randomly assigned in groups of two to eight to one of four conditions created by crossing the mood (good vs. neutral) and expectancy (one group vs. two group) variables.

Procedure The procedure in Experiment 2 was similar to the procedure used in Experiment 1 , with several notable changes. To simplify the design (and because of the lack of order effects in Experiment 1), the target groups and mood-inducing video excerpts were presented in a set order in Experiment 2.
Participants' expectations regarding the number of groups they would read about were also manipulated. Participants were led to believe either that they would be receiving information describing the members of one group (one-group expectancy) or were given the same instructions provided in Experiment 1 (two-group expectancy). Specifically, whereas some participants were instructed that, 'you will read about some behaviors that were performed by the members of a group that we are calling Group A', other participants were told that they would 'read about some behaviors that were performed by the members of groups that we are calling either Group A or Group B. First you will be reading about the members of Group A. Later, you will be reading about the members of Group B'. In both cases, however, participants read about the first group, Group A, made an intragroup similarity judgment for that group, and then were asked to form an impression of another group, Group B. After judging the variability with Group B, all participants judged the similarity of the two groups, as in Experiment 1. Therefore, the key difference between the two experiments was that individuals in the one group expectancy condition of Experiment 2 thought they would only form an impression of one group as they processed the information describing the members of Group A. Finally, after completing all judgments of the groups, participants were given three minutes to recall as many of the behavioral sentences as they could.

\section{Results and discussion}

Effectiveness of mood manipulations Responses to the two manipulation check items were again highly correlated for the first and second mood inductions $(r s=.79$ and .70 , respectively), and they were therefore averaged for each induction and submitted to a 2 $($ Mood $) \times 2$ (Expectancy) $\times 2$ (Induction) ANOVA with repeated measures on the last factor. Participants in the positive mood condition reported being happier $(M=6.5)$ than participants in the neutral mood condition $(M$ $=5.2)(F(1,114)=49.67, p<.001)$, and $\operatorname{mood}$ ratings were generally higher after the first 
mood induction than after the second $(M \mathrm{~s}=6.2$ vs. 5.5, respectively) $(F(1,114)=18.23, p<$ $.001)$. Separate one-way ANOVAs were significant for both the first $(F(1,116)=32.46, p<$ $.001)$, and second $(F(1,116)=22.21, p<.001)$, inductions, indicating that both manipulations were successful in inducing the desired mood states. As in Experiment 1, participants' moods in the neutral $(M=5.2)$ and happy $(M=5.0)$ conditions did not differ at the end of the experiment $(F<1)$.

\section{Effects of mood on perceptions of variability}

Within-group similarity Responses to the two items assessing perceived within-group variability were submitted to a 2 (Mood) $\times 2$ (Expectancy) $\times 2$ (Group) ANOVA with repeated measures on the last variable. This analysis yielded an Expectancy main effect $(F(1$, $114)=7.40, p<.01)$, which was qualified by a significant, predicted three-way interaction $(F(1,114)=4.90, p<.05) \quad($ see Figure 1$)$. To better understand the nature of the interaction, separate 2 (Mood) $\times 2$ (Expectancy) ANOVAs were conducted on the judgments of the two groups. The analysis of the judgments of Group A, the first group participants read about, yielded a Mood effect $(F(1,114)=3.83, p<.05)$, an Expectancy effect $(F(1,114)=6.72, p<.01)$, and a significant Mood X Expectancy interaction $(F(1,114)=5.03, p<.05)$. As displayed in the top panel of Figure 1, participants who expected to receive information about only one group judged the members of Group A as more similar to one another when they were in a positive $(M=5.2)$ compared with a neutral $\operatorname{mood}(M=4.0)(F(1,56)=9.00, p<.01)$. In contrast, judgments of Group A's within-group variability were not affected by mood when participants expected to learn about two groups $(M \mathrm{~s}=5.3$ vs. 5.4 , respectively). Furthermore, the comparison examining the impact of expectancy within the neutral mood condition was significant $(F(1,56)=13.43, p<.01)$, whereas the identical analysis in the positive mood condition was not $(F<1)$. Analyses of judgments of the second group participants read about, Group B (lower panel, Figure 1), yielded no significant effects (all $p \mathrm{~s}>.19$ ). Con- sistent with predictions, individuals in a neutral mood were more likely to detect the variability within a group when they expected to learn only about that group. Individuals in a neutral mood made higher similarity judgments, as high as those of individuals in a positive mood, when they expected to learn about two groups.

Between-group differentiation Replicating Experiment 1 , responses to the items about the general similarities and differences of the groups reflected significant effects of mood. As can be seen in Table 2, individuals in a positive mood perceived the groups as more similar $(F(1,114)=6.97, p<.01)$, and less different $(F(1,113)=4.33, p<.05)$, than individuals in a neutral mood. ${ }^{2}$ Judgments of the differences and similarities in friendliness yielded similar effects. Participants in a happy mood viewed the groups as more similar $(F(1,113)=4.09, p$ $<.05)$, and marginally less different $(F(1,114)$ $=3.17, p=.08)$, than did participants in a neutral mood. Judgments of comparative intelligence again produced no effects (both $p s>$ $.50)$. Replicating the findings of Experiment 1, positive mood decreased differentiation between the groups in general and on relevant traits in particular.

Free recall Recall data were analyzed to assess the degree to which available information was deliberatively processed. An experimenter blind to experimental conditions coded the free recall protocols using a 'gist' criterion, and the total number of items recalled was calculated. It was expected that recall would be higher in the neutral than positive mood condition, indicating greater systematic processing of the behavioral information. To test this hypothesis, data were entered into a 2 (Mood) $\times 2$ (Expectancy) $\times 2$ (Group) ANOVA with repeated measures on the last factor. This analysis yielded a Group main effect $(F(1,114)$ $=36.87, p<.001)$, indicating that more items were recalled that described Group B, the last group about which participants read, than Group A ( $M \mathrm{~s}=6.4$ vs. 5.4, respectively). Of greater theoretical interest was a marginally significant effect of $\operatorname{Mood}(F(1,114)=3.60$, 

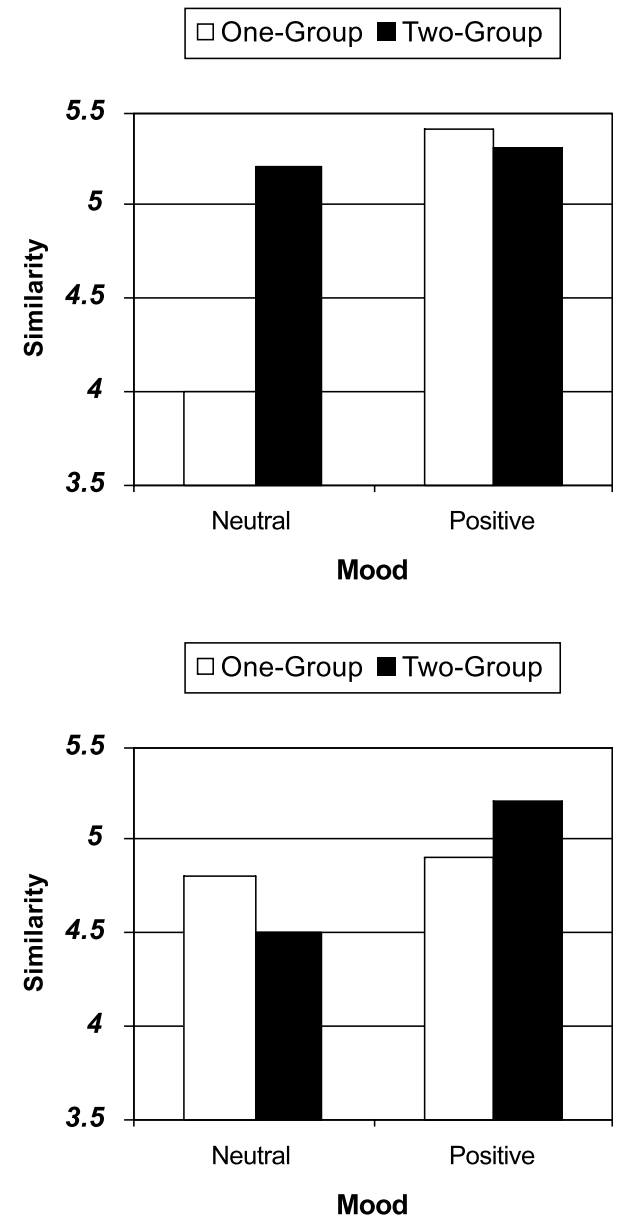

Figure 1. Judgments of within-group similarity of Group A (top panel) and Group B (bottom panel) as a function of mood and expectancy, Experiment 2.

Table 2. Mean between-group differentiation judgments as a function of mood: Experiment 2

\begin{tabular}{lcc}
\hline & \multicolumn{2}{c}{ Mood } \\
\cline { 2 - 3 } Judgment & Neutral & Positive \\
\hline General similarity & 3.6 & 4.4 \\
Friendliness similarity & 3.7 & 4.3 \\
Intelligence similarity & 4.4 & 4.6 \\
General difference & 6.1 & 5.5 \\
Friendliness difference & 6.1 & 5.5 \\
Intelligence difference & 5.0 & 5.0 \\
\hline
\end{tabular}


$p=.06)$, indicating that, as predicted, participants in a neutral mood recalled more items about each group $(M=6.1)$ than did participants in a good $\operatorname{mood}(M=5.7)$.

The data were generally consistent with predictions. Regarding the detection of variability within groups, individuals expecting to form impressions of a single group judged the group as homogeneous when in a happy mood and heterogeneous when in a neutral mood. When they expected to learn about two groups, however, perceived variability within the first group was equally homogeneous. We believe this to be the first evidence that group expectancies and mood interact to affect perceived variability within groups. Regarding differentiation, the recall data provide some support for the interpretation that positive mood decreased differentiation because happiness reduced deliberative processing of available information. The conditions in which processing appeared less deliberate were also the conditions in which similarity judgments were highest. If low levels of deliberation undermined differentiation, one might expect that more deliberative processing (as reflected in the amount of free recall) should be associated with greater differentiation between groups (as reflected in the judgments of similarity and difference). In fact, the mean number of items recalled was significantly correlated with a composite of the differentiation measures (the average of the difference and reverse-scored similarity items $)(r(117)=.30$, $p<.01)$.

Despite these generally supportive findings, a third experiment was conducted with several goals in mind. The main goal was to collect data that could provide a stronger test of the role of deliberative processing in the relation between mood and differentiation. It was hoped that Experiment 2 might allow a test of the mediational role of deliberative processing in the relation between mood and differentiation. However, a significant effect of the independent variable (mood) on the potential mediator (free recall) is necessary for such a test, and this effect was only marginally significant. In retrospect, we suspected that the manner in which the recall data were collected might have limited their usefulness for providing a direct test of this hypothesis. Because Experiment 2 focused on variability judgments, recall was collected after all other judgments had been made. This was done so that the collection of free recall would not contaminate judgments of variability. However, it is quite possible that the reverse occurred; free recall might have been affected by the judgments that had already been made. If so, the method in Experiment 2 might have worked against the use of recall as a measure of deliberative processing since the quantity and content of recall might have been contaminated by participants' judgments. A superior approach, then, would be to collect recall before group judgments are made. This was one change that was made in Experiment 3.

\section{Experiment 3}

In addition to changing the timing of the collection of free recall, we made several other changes to rule out alternate explanations and increase confidence in the generality of the findings. ${ }^{3}$ First, a different mood manipulation was used in Experiment 3. Showing similar effects with different manipulations of mood would enhance the likelihood that mood, and not the nature or the content of the manipulation, plays a causal role in affecting variability judgments. Second, the nature of group differences was modified to remove valence as a basis of group differentiation. Because the groups differed in valence and the potential importance of valence for individuals differing in mood states, it seemed prudent to attempt a replication with groups that differed in alternate ways. Individuals in Experiment 3, therefore, formed impressions of groups that differed on average in the positive characteristic they tended to display. One group's members primarily acted in a friendly, and the other primarily in an intelligent, manner. Third, the order in which individuals were queried about group differences was modified. In the first two experiments, participants were asked about similarities before being asked about 
differences between groups. Although analyses of these two items produced nearly identical conclusions, it was possible that the ordering of items might have artificially exaggerated reported similarity particularly among happy participants. As mentioned above, happy individuals in Murray et al.'s (1990) study showed that they were able to generate more similarities and more differences between stimuli compared with individuals in a neutral mood. It was therefore possible that asking to judge similarity first and only then to judge difference within groups might have focused participants on the former. Although such effects did not emerge in their research when the same participants generated both similarities and differences (Murray et al., 1990, Study 2), we wanted to rule out the possibility that the ordering of similarity items influenced our substantive conclusions. Therefore, individuals in this experiment judged differences between groups before judging their similarity.

\section{Method}

Participants Altogether, 112 undergraduates participated in exchange for partial course credit.

Stimulus materials The primary variables in this study again were mood (good vs. neutral) and expectancy (one group vs. two group), but the mood manipulation and the nature of the groups differed. The Velton (1968) procedure was utilized to induce a good or neutral mood. In this procedure, participants are provided with a set of 60 statements that they read for 20 seconds each. These statements are either selfreferential and indicative of elated mood (i.e. designed to induce a happy mood) or are unrelated to the self or to mood (i.e. to induce a neutral mood). Because of the need to manipulate mood before the presentation of information about each group, participants completed the procedure twice with 30 items in each set.

New behavioral descriptions were used to convey information about groups that tended to be either friendly or intelligent but were also highly variable. These descriptions were based on ratings $(N=20)$ of 60 new behavioral items for both intelligence and friendliness on a 9point scale. These ratings were used to create 12-item sets describing Group A, whose members were friendly $(M=6.4)$ but neutral with regard to intelligence $(M=5.1)$, and Group B, whose members were intelligent $(M=$ 6.4) but neutral with regard to friendliness $(M$ $=5.0$ ). Both groups showed a high level of variability around these averages $(S D \mathrm{~s}=1.7$ and 1.6 , respectively).

Procedure Procedures for Experiments 2 and 3 were similar. In both experiments, participants completed two mood inductions to induce a good or neutral mood and formed impressions of two groups under a one-group or two-group expectancy. However, participants' moods in Experiment 3 were manipulated through use of the Velten (1968) procedure. After the first mood induction, participants completed a mood manipulation check and then read the items describing behaviors performed by the members of Group A, one at a time for six seconds each. To clear short-term memory, participants then were handed a map of the United States with state boundaries but no state names indicated. They were asked to write the name of each state within its boundaries, and they were given three minutes to complete this task. After two minutes, free recall was collected for three minutes. Participants then completed the intragroup similarity scale for that group. Participants completed this procedure again, except they were provided with descriptions of behaviors performed by Group B. After both impression formation and recall tasks were completed, participants judged the similarity of the two groups (with items about difference appearing first).

\section{Results and discussion}

Effectiveness of mood manipulations Because responses to the manipulation check items were highly correlated for both mood inductions $(r \mathrm{~s}=.78$ and .82 , respectively), they were averaged and analyzed using a 2 (Mood) $\times 2$ (Expectancy) $\times 2$ (Induction) ANOVA with 
repeated measures on the last factor. Participants in the positive mood conditions reported being happier $(M=7.0)$ than participants in the neutral mood condition $(M=5.3)(F(1,108)=$ $111.20, p<.001)$. No other effects were significant, suggesting that the mood manipulation was equally effective for both inductions.

Free recall A 2 (Mood) $\times 2$ (Expectancy) $\times 2$ (Group) ANOVA of free recall produced only a significant effect of $\operatorname{Mood}(F(1,108)=8.06, p<$ $.01)$. Participants in a neutral mood recalled more items overall than did participants in a $\operatorname{good} \operatorname{mood}(M \mathrm{~s}=12.2$ vs. 10.7, respectively). These recall data, collected before other judgments were collected, provide clearer evidence of differences in systematic processing between individuals in a good and neutral mood.

\section{Effects of mood on perceptions of variability}

Within-group similarity An analysis of withingroup variability judgments again yielded an Expectancy effect $(F(1,108)=10.04, p<.01)$, qualified by a three-way interaction $(F(1,108)=$ $5.53, p<.05)$. An analysis of the judgments of Group A produced a Mood effect $(F(1,108)=$ $6.59, p<.05)$, an Expectancy effect $(F(1,108)=$ $10.39, p<.01)$, and a two-way interaction $(F(1$, $108)=5.84, p<.05)$. Replicating the pattern of findings in Experiment 2, happy individuals who expected to learn about one group judged the group as more similar than did individuals in a neutral mood $(M \mathrm{~s}=5.4$ vs. 4.0 , respectively) $(F(1,108)=13.05, p<.01)$. Under the expectation of two groups, however, there was no difference between the mood conditions
$(M s=5.6$ vs. 5.5$)(p=.92)$. There were no significant effects for judgments of Group B. As in Experiment 2, neutral mood facilitated the recognition of diversity only under the expectation of a single group.

Between-group differentiation Consistent with the previous two experiments, individuals in a positive mood perceived the groups as more similar $(F(1,108)=6.34, p<.05)$, and less different $(F(1,108)=6.25, p<.05)$, than did individuals in a neutral mood (See Table 3 ). Judgments on the specific traits yielded parallel findings. On judgments of friendliness, happy participants viewed the groups as marginally more similar $(F(1,108)=3.05, p=.08)$, and marginally less different $(F(1,108)=3.10, p=$ $.08)$, than did participants in a neutral mood. On judgments of intelligence, happy participants viewed the groups as more similar $(F(1$, $108)=5.31, p<.05)$, and less different $(F(1$, $108)=4.13, p<.05)$, than did participants in a neutral mood. Thus, happy mood decreased differentiation even with different question ordering, and the effects were apparent on both traits on which the groups differed in this experiment.

Mediational analyses Mediational analyses were conducted to test causal role of deliberative processing in perceptions of within- and between-group variability. Differences in deliberative processing were hypothesized to account for differences between mood groups in the recognition of high within-group variability. However, these relations were expected

Table 3. Mean between-group differentiation judgments as a function of mood: Experiment 3

\begin{tabular}{lcc}
\hline & \multicolumn{2}{c}{ Mood } \\
\cline { 2 - 3 } Judgment & Neutral & Positive \\
\hline General similarity & 4.4 & 5.1 \\
Friendliness similarity & 3.7 & 4.2 \\
Intelligence similarity & 3.9 & 4.5 \\
General difference & 5.3 & 4.6 \\
Friendliness difference & 6.1 & 5.5 \\
Intelligence difference & 5.7 & 5.4 \\
\hline
\end{tabular}


only for the first group encountered and only under a one-group expectancy. To test this, a series of regression analyses were performed (Kenny, Kashy, \& Bolger, 1998) using codes for the different mood conditions and measures of deliberative processing (i.e. free recall for each group) and similarity (i.e. the within-group similarity item). As predicted, evidence for mediation was obtained only in the oneexpectancy condition for the judgment of the first group. In this condition, mood predicted similarity $(\beta=.22 ; t(56)=2.4, p<.05)$, and free recall $(\beta=-.27 ; t(56)=-3.0, p<.01)$. Most important for establishing mediation, free recall predicted similarity after controlling for $\operatorname{mood}(\beta=-.26 ; t(56)=-2.8, p<.01)$. The impact of mood on similarity was significantly reduced when the mediator was included (Sobel test, $Z=-2.0, p<.05$ ).

To examine the causal role of deliberation in the relation between mood and differentiation, regression analyses were performed using codes for mood groups and measures of deliberative processing (i.e. total free recall) and differentiation between groups (i.e. the average of the general difference and reverse-scored general similarity items). Mood predicted differentiation $(\beta=-.25 ; t(110)=-2.7, p<.01)$, and free recall $(\beta=-.27 ; t(110)=-3.0, p<.01)$, and free recall predicted differentiation after controlling for $\operatorname{mood}(\beta=.25 ; t(109)=2.7, p<$ $.01)$. The impact of mood on differentiation was reduced significantly when the mediator was included (Sobel test, $Z=-2.0, p<.05){ }^{4}$ These analyses indicate that deliberative processing mediated the relationship between mood, similarity, and differentiation as hypothesized.

\section{General discussion}

Three studies showed that mood affects the perception of differences within and between novel groups. Perceivers in a positive mood were less likely to differentiate between two groups whose members were, on average, quite different from each other. Judgments of variability within each group, however, were affected in more complex ways. Intragroup vari- ability judgments were affected both by mood states and expectations about the number of groups to be encountered. These results have implications for theories of mood and cognitive processing, for the literatures on group differentiation and homogeneity, and for theories focusing on the consequences of intergroup contact. We discuss these implications in turn.

\section{Mood and cognitive processing}

These studies were not designed to distinguish mood theories, but they nonetheless speak to several issues relevant to differing accounts of mood. First, it is clear that positive mood did not produce highly deliberative processing as it has in some other contexts. Although positive moods can lead to generative, varied, and flexible responses to stimuli, these results typically emerge when tasks are engaging and enjoyable (Isen, 1999). In the context of an impression formation task demanding attention and effortful deliberation to ensure accuracy, positive mood clearly undermined deliberative processing. As we have argued above, however, the consequences of reduced processing were mixed in regard to intergroup perception. Whereas perceptions of homogeneity were increased, intergroup differentiation was diminished.

Second, these results cannot easily be explained by models focusing on the increased reliance of individuals in a happy mood on preexisting knowledge structures (Bless, Schwarz, \& Kemmelmeier, 1996; Bodenhausen et al., 1994; Krauth-Gruber \& Ric, 2000). Although there are considerable data supporting this account when existing groups are involved, this account is largely silent regarding the formation of impressions of novel groups. No pre-existing stereotypes existed of the novel groups we used in our studies, and therefore, it was not surprising that mood had no impact on judgments of the traits possessed by group members. Instead, the effects of mood were revealed primarily on perceived variability within and between groups, judgments reliant on the ability to systematically process information about similarities and differences. Therefore, where novel groups are involved, theories that focus on the processing 
deficits associated with positive mood are most likely to hold sway (Mackie \& Worth, 1991; Schwarz, 1990).

\section{Mood and the perception of differences between groups}

Positive mood decreased the differentiation between the two novel groups, in part because happiness reduced deliberative processing of available information. In two experiments, happy participants recalled less information about the groups, and Experiment 3 showed that the amount of recall was shown to mediate the relation between mood and differentiation. So, for these very different novel groups, positive mood appeared to decrease differentiation by decreasing the thoroughness of processing.

Decreased thoroughness of processing under positive mood should not always reduce differentiation. If there were no real group differences, in fact, positive mood might lead to greater differentiation. This might occur if perceivers in a positive mood simply rely on group labels to infer differences where none, in fact, exist. This is exactly what was found in a recent paper by Abele, Gendolla, and Petzold (1998). In their studies, individuals underwent a positive mood or no mood induction after being divided into groups via the minimal group paradigm. Participants in the positive mood conditions were more likely to discriminate between ingroup and outgroup members in evaluative ratings, suggesting that they saw the members of the ingroup and outgroups as particularly distinct compared with those participants in a neutral mood. In the Abele et al. study, there were no actual differences between groups (because of the random assignment of participants into groups), whereas the groups in our study were created to differ substantially from each other. Therefore, we suggest that our findings are compatible with those of Abele et al. in that participants in a neutral mood were more accurate in detecting the presence (or absence) of real group differences. In their study, where there were no differences between the groups, participants in a neutral mood were less likely to differentiate between the groups in their evaluative ratings. In our study, where there were group differences, participants in a neutral mood made lower similarity ratings, indicating that they accurately detected that the groups were different.

We suggest then that mood effects on differentiation depend on the actual degree of difference between groups. If groups are highly similar, then positive mood, due to the use of group labels as a heuristic cue indicating difference, will increase perceived differences and will facilitate between-group discrimination. If groups are highly different, however, positive mood would be expected to attenuate the perception of difference. This allows for the possibility that with a moderate degree of group difference, individuals in a neutral and positive mood might make equivalent judgments of similarity. They might do so for different reasons, however, due to deliberative processing in the former and heuristic processing in the latter condition.

\section{Mood and the perception differences within groups}

Judgments of intragroup variability were affected in a more complex manner by mood. Specifically, mood interacted with expectations about the number of target groups to affect perceived intragroup similarity. Participants in a happy mood failed to detect the variability within either group, regardless of whether they expected to form an impression of one or two groups. Participants in a neutral mood, however, showed greater detection of variability only when one group was expected. We suspect that expectancies regarding the number of groups prompted different processes during the impression formation process. When two groups were expected, we believe that participants did not focus their attentional resources on detecting the variability within either group. When only a single group was expected, however, participants in a neutral mood paid particular attention to the variability contained within the first group encountered. Thus, for participants in a neutral mood, the lower variability judgments in the condition in which two 
groups were expected likely arose because of differing information processing goals in a multiple-group context, not because they were unable or unwilling to process information deliberately.

Of course, the processing of information by participants in a neutral mood was not so thorough that they were able to detect withingroup variability when it was not the focus of attentional resources. Participants in a neutral mood had some ability to process the information as evidenced by their ability to discriminate between the two groups. Discriminating between members of the same group, however, was negatively affected by expectancies regarding the number of target groups. Thus, it appears that individuals in a neutral mood allocated their somewhat limited attentional resources on processing the information seen as most relevant to the task at hand. On the one hand, when detecting differences between groups was seen as most informative or important (i.e. when forming impressions of two groups), detection of within group variability was neglected. On the other hand, when making distinctions among group members seemed most important (i.e. when forming an impression of a single group), participants in a neutral mood were more likely to detect the high degree of variability within the group. To our knowledge, this is the first time this effect has been reported, and it seems to be an issue worth pursuing in its own right. Future studies could advance our understanding of these processing differences by measuring attention to behavioral information that denotes high variability under single versus multiple-group expectations.

However, the finding that the focus of information processing can shift as a function of an interaction between perceiver characteristics and the informational environment is not without some precedent. This finding is analogous to one reported by Pendry and Macrae (1999), who examined the impact of cognitive load and variability on the formation of an impression of a single novel group. They found that under optimal processing conditions, participants tended to recall more stereotypic information when the group was homogeneous, but more counterstereotypic information when the group was heterogeneous. Under reduced cognitive capacity, however, participants tended to recall stereotypic information, regardless of the variability of the group. The similarity of the results in their high cognitive load and our positive mood conditions is consistent with our interpretation that our effects emerged because of the processing deficits associated with positive mood.

\section{Implications for intergroup perception}

Positive mood appears to have both beneficial and detrimental consequences for group perception. Although happiness appears to decrease perceived variability within groups, it can also make distinctive groups appear to be similar. In addition, some evidence suggests that positive mood decreases the distinction of the self from an undesirable group, suggesting that individuals in a positive mood might be more willing to interact with members of disliked outgroups.

In addition to highlighting the complex role of mood in the formation of group impressions, these data are also suggestive about how group information might ideally be presented when individuals are in a neutral mood. It appears as if the informational context is a factor that can influence whether the variability within a group is detected. If individuals believe they will form an impression of a single group, they are likely motivated to form both an impression of a groups' typical characteristics (i.e. the central tendency) and the degree that members of the group differ from what is typical for the group (i.e. intragroup variability). If individuals receive information about multiple groups (or merely when they expect to do so), the detection of variability within the groups is attenuated. Under these circumstances, individuals are likely motivated to attend more to detecting the typical characteristics of the group to allow a comparison with other groups who will be encountered. Consequently, the variability within the group may be perceived as less important, given the perceivers' emphasis on comparing one group with another. 
Therefore, it may be beneficial to deemphasize comparisons with other groups when presenting individuals with information describing novel groups. If individuals are forming impressions of an unfamiliar group, the variability within the group might thus be better recognized from the outset. Once an impression of a single group has been formed, comparisons between groups might then be emphasized without negatively affecting the recognition of variability within the groups being compared. It appears that the mere expectation of multiple targets is sufficient to reduce the detection of differences within either group. Given the increasing diversity of contemporary social environments, further consideration of the impact of learning about groups in isolation or through explicit comparison with others might prove beneficial.

\section{Notes}

1. The variability of these behavioral sets was similar to the highly variable (HV) set used in Stroessner and Mackie (1992).

2. One participant did not respond to the item about general difference and another to the question about similarities in friendliness. Analyses excluding these participants yielded similar results.

3. We thank two anonymous reviewers for their comments that prompted these modifications.

4. Mediational analyses in which the mood manipulation check data served as the predictor variable yielded similar results.

\section{Acknowledgements}

We are indebted to Nelly Sta. Maria, Michelle Berger Brookstein, Catita Perron, and Deborah Katz for their contributions in creating materials and collecting and coding data. Preparation of this article was supported by NSF Grants 9709797 and 9911004 to the first author.

\section{References}

Abele, A., Gendolla, G. H. E., \& Petzold, P. (1998). Positive mood and in-group-out-group differentiation in a minimal group setting.
Personality and Social Psychology Bulletin, 24, 1343-1357.

Allport, G. W. (1954). The nature of prejudice. Cambridge, MA: Addison-Wesley.

Amir, Y. (1969). Contact hypothesis in ethnic relations. Psychological Bulletin, 71, 319-342.

Ashby, F. G., Isen, A. M., \& Turken, U. (1999). A neuropsychological theory of positive affect and its influence on cognition. Psychological Review, 106, 529-550.

Berkowitz, L. (1993). Towards a general theory of anger and emotional aggression: Implications of the cognitive-neoassociationistic perspective for the analysis of anger and other emotions. In R. S. Wyer \& T. K. Srull (Eds.), Advances in social cognition (Vol. 6, pp. 1-46). Mahwah, NJ: Erlbaum.

Bless, H., Bohner, G., Schwarz, N., \& Strack, F. (1990). Mood and persuasion: A cognitive response analysis. Personality and Social Psychology Bulletin, 16, 331-345.

Bless, H., Clore, G. L., Schwarz, N., Golisano, V., Rabe, C., \& Wölk, M. (1996). Mood and the use of scripts: Does a happy mood really lead to mindlessness? Journal of Personality and Social Psychology, 71, 665-679.

Bless, H., \& Fiedler, K. (1995). Affective states and the influence of activated general knowledge. Personality E Social Psychology Bulletin, 21, 766-778.

Bless, H., Mackie, D. M., \& Schwarz, N. (1992). Mood effects on encoding and judgmental processes in persuasion. Journal of Personality and Social Psychology, 63, 585-595.

Bless, H., Schwarz, N., \& Kemmelmeier, M. (1996). Mood and stereotyping: Affective states and the use of general knowledge structures. In W. Stroebe \& M. Hewstone (Eds.), European review of social psychology (Vol. 7, pp. 63-93). Chichester, UK: Wiley.

Blessum, K. A., Lord, C. G., \& Sia, T. L. (1998). Cognitive load and positive mood reduce typicality effects in attitude-behavior consistency. Personality and Social Psychology Bulletin, 24, 496-504.

Bodenhausen, G. V. (1993). Emotions, arousal, and stereotypic judgments: A heuristic model of affect and stereotyping. In D. M. Mackie \& D. L. Hamilton (Eds.), Affect, cognition, and stereotyping: Interactive processes in group perception (pp. 13-37). San Diego, CA: Academic Press.

Bodenhausen, G. V., Kramer, G., \& Süsser, K. (1994). Happiness and stereotypical thinking in social judgment. Journal of Personality and Social Psychology, 66, 621-632.

Bodenhausen, G. V., Mussweiler, T., Gabriel, S., \& 
Moreno, K. N. (2001). Affective influences on stereotyping and intergroup relations. In J. P. Forgas (Ed.), Handbook of affect and social cognition (pp. 319-343). Mahwah, NJ: Erlbaum.

Bower, G. H. (1991). Mood congruity of social judgments. In J. P. Forgas (Ed.), Emotion and social judgments (pp. 31-54). New York: Pergamon Press.

Brewer, M. B. (1979). In-group bias in the minimal intergroup situation: A cognitive-motivational analysis. Psychological Bulletin, 36, 307-324.

Brewer, M. B., \& Miller, N. (1984). Beyond the contact hypothesis: Theoretical perspectives on desegregation. In N. Miller \& M. B. Brewer (Eds.), Groups in contact: The psychology of desegregation (pp. 281-302). Orlando, FL: Academic Press.

Campbell, D. T. (1956). Enhancement of contrast as a composite habit. Journal of Abnormal and Social Psychology, 53, 350-355.

Doise, W., Deschamps, J. C., \& Meyer, G. (1978). The accentuation of intra-category similarities. In H. Tajfel (Ed.), Differentiation between social groups: Studies in the social psychology of intergroup relations. London: Academic Press.

Dovidio, J. F., Gaertner, S. L., Isen, A. M., \& Lowrance, R. (1995). Group representations and intergroup bias: Positive affect, similarity, and group size. Personality and Social Psychology Bulletin, 21, 856-865.

Dreisbach, G., \& Goschke, T. (2004). How positive affect modulates cognitive control: Reduced perseveration at the cost of increased distractibility. Journal of Experimental Psychology: Learning, Memory, E Cognition, 30, 343-353.

Eiser, J. R. (1971). Enhancement of contrast in the absolute judgment of attitude statements. Journal of Personality and Social Psychology, 17, 1-10.

Ellis, H. C., \& Ashbrook, T. W. (1988). Resource allocation model of the effects of depressed mood state on memory. In K. Fiedler \& J. P. Forgas (Eds.), Affect, cognition, and social behavior (pp. 25-43). Göttingen, Germany: Hogrefe.

Ford, T. E., \& Stangor, C. (1992). The role of diagnosticity in stereotype formation: Perceiving group means and variances. Journal of Personality and Social Psychology, 63, 356-367.

Forgas, J. P. (1995). Mood and judgment: The Affect Infusion Model (AIM). Psychological Bulletin, 116, 39-66.

Forgas, J. P., \& Fiedler, K. (1996). Us and them: Mood effects on intergroup discrimination. Journal of Personality and Social Psychology, 70, 28-40.

Forgas. J. P., \& Moylan, S. J. (1991). Affective influences on stereotype judgments. Cognition and Emotion, 5, 379-395.

Hamilton, D. L., \& Sherman, J. W. (1994). Stereotypes. In R. S. Wyer \& T. K. Srull (Eds.), Handbook of social cognition (pp. 1-68). Hillsdale, NJ: Erlbaum.

Isen, A. M. (1987). Positive affect, cognitive processes and social behavior. In L. Berkowitz (Ed.), Advances in experimental social psychology (Vol. 20, pp. 203-253). San Diego, CA: Academic Press.

Isen, A. M. (1993). Positive affect and decision making. In M. Lewis \& J. M. Haviland (Eds.), Handbook of emotion (pp. 261-277). New York: Guilford.

Isen, A. M. (1999). Positive affect. In T. Dalgleish \& M. Powers (Eds.), The handbook of cognition and emotion (pp. 75-94). Hillsdale, NJ: Erlbaum.

Isen, A. M., \& Daubman, K. A. (1984). The influence of affect on categorization. Journal of Personality and Social Psychology, 47, 1206-1217.

Isen, A. M., Johnson, M. M. S., Mertz, E., \& Robinson, G. F. (1985). The influence of positive affect on the unusualness of word associations. Journal of Personality and Social Psychology, 48, 1413-1426.

Isen, A. M., Niedenthal, P., \& Cantor, N. (1992). An influence of positive affect on social categorization. Motivation and Emotion, 16, 65-78.

Jetten, J., Spears, R., \& Manstead, A. S. R. (1998). Defining dimensions of distinctiveness: Group variability makes a difference to differentiation. Journal of Personality and Social Psychology, 74, 1481-1492.

Kenny, D. A., Kashy, D. A., \& Bolger, N. (1998). Data analysis in social psychology. In D. T. Gilbert, S. T. Fiske, \& G. Lindzey (Eds.), Handbook of social psychology (pp. 233-265). Boston: McGraw-Hill. Krauth-Gruber, S., \& Ric, F. (2000). Affect and stereotypic thinking: A test of the moodand-general-knowledge model. Personality and Social Psychology Bulletin, 26, 1587-1597.

Krueger, J., \& Rothbart, M. (1990). Contrast and accentuation effects in category learning. Journal of Personality and Social Psychology, 59, 651-663.

Krueger, J., Rothbart, M., \& Sriram, N. (1989). Category learning and change: Differences in sensitivity to information that enhances or reduces intercategory distinctions. Journal of Personality and Social Psychology, 56, 866-875.

Leith, K. P., \& Baumeister, R. F (1996). Why do bad moods increase self-defeating behavior? Emotion, risk tasking, and self-regulation. Journal of Personality and Social Psychology, 71, 1250-1267.

Linville, P. W., Salovey, P., \& Fischer, G. W. (1986). 
Stereotyping and perceived distributions of social characteristics: An application to ingroupoutgroup perception. In J. Dovidio \& S. L. Gaertner (Eds.), Prejudice, discrimination, and racism (pp. 165-208). New York: Academic Press.

Mackie, D. M., \& Hamilton, D. L. (Eds.) (1993). Affect, cognition, and stereotyping: Interactive processes in group perception. San Diego, CA: Academic Press.

Mackie, D. M., Queller, S., Stroessner, S. J., \& Hamilton, D. L. (1996). Making stereotypes better or worse: Multiple roles for positive affect in group impressions. In R. M . Sorrentino \& E. T. Higgins (Eds.), Handbook of motivation and cognition: Vol. 3. The interpersonal context (pp. 371-396). New York: Guilford.

Mackie, D. M., \& Worth, L. T. (1989). Processing deficits and the mediation of positive affect in persuasion. Journal of Personality and Social Psychology, 57, 27-40.

Mackie, D. M., \& Worth, L. T. (1991). Feeling good, but not thinking straight: The impact of positive mood on persuasion. In J. P. Forgas (Ed.), Emotion and social judgements (pp. 209-219). New York: Pergamon Press.

Mayer, J. D., Gaschke, Y. N., Braverman, D. L., \& Evans, T. W. (1992). Mood congruent judgment is a general effect. Journal of Personality and Social Psychology, 63, 119-132.

Melton, J. R. (1995). The role of positive affect in syllogism performance. Personality and Social Psychology Bulletin, 21, 788-794.

Murray, N., Sujan, H., Hirt, E. R., \& Sujan, M. (1990). The influence of mood on categorization: A cognitive flexibility interpretation. Journal of Personality and Social Psychology, 59, 411-425.

Park, J., \& Banaji, M. R. (2000). Mood and heuristics: The influence of happy and sad states on sensitivity and bias in stereotyping. Journal of Personality and Social Psychology, 78, 1005-1023.

Pendry, L. F., \& Macrae, C. N. (1999). Cognitive load and person memory: The role of perceived group variability. European Journal of Social Psychology, 29, 925-942.

Phillips, L. H., Bull, R., Adams, E., \& Fraser, L. (2002). Positive mood and executive function: Evidence from Stroop and fluency tasks. Emotion, 2, 12-22.

Quattrone, G. A. (1986). On the perception of a group's variability. In S. Worchel \& W. Austin (Eds.), The Psychology of intergroup relations (2nd ed., pp. 25-48). Chicago: Nelson-Hall.

Queller, S., Mackie, D. M., \& Stroessner, S. J. (1996). Ameliorating some negative effects of positive mood: Encouraging happy people to perceive intragroup variability. Journal of Experimental Social Psychology, 32, 361-386.

Rothbart, M., Davis-Stitt, C., \& Hill, J. (1997). Effects of arbitrarily placed category boundaries on similarity judgements. Journal of Experimental Social Psychology, 33, 122-145.

Schwarz, N. (1990). Feelings as information: Informational and motivational functions of affective states. In R. Sorrentino \& E. T. Higgins (Eds.), Handbook of motivation and cognition: Foundations of social behavior (Vol. 2, pp. 527-561). New York: Guilford.

Schwarz, N., \& Clore, G. L. (1996). Feelings and phenomenal experiences. In E. T. Higgins \& A. W. Kruglanski (Eds.), Social psychology. Handbook of basic principles (pp. 433-465).

Sinclair, R. C., \& Mark, M. M. (1995). The effects of mood state on judgmental accuracy: Processing strategy as a mechanism. Cognition and Emotion, 9, 417-438.

Spies, K., Hesse, F. W., \& Hummitzsch, C. (1996). Mood and capacity in Baddeley's model of human memory. Zeitschrift für Psychologie, 204, 367-381.

Stroessner, S. J., Hamilton, D. L., \& Mackie, D. M. (1992). Affect and stereotyping: The effect of induced mood on distinctiveness-based illusory correlations. Journal of Personality and Social Psychology, 62, 564-576.

Stroessner, S. J., \& Mackie, D. M. (1992). The impact of induced affect on the perception of variability in social groups. Personality and Social Psychology Bulletin, 18, 546-554.

Stroessner, S. J., \& Mackie, D. M. (1993). Affect and perceived group variability: Implications for stereotyping and prejudice. In D. M. Mackie \& D. L. Hamilton (Eds.), Affect, cognition, and stereotyping: Interactive processes in group perception (pp. 63-86). San Diego, CA: Academic Press.

Tajfel, H., \& Wilkes, A. L. (1963). Classification and quantitative judgment. British Journal of Social Psychology, 54, 101-114.

Turner, J. C. (1991). Social influence. Buckingham, UK: Open University Press.

Velton, E. (1968). A laboratory task for induction of mood states. Behavior Research and Therapy, 6, 473-482.

Wegener, D. T., Petty, R. E., \& Smith, S. M. (1995). Positive mood can increase or decrease message scrutiny: The hedonic contingency view of mood and message processing. Journal of Personality and Social Psychology, 69, 5-15.

Wilder, D. A. (1986). Social categorization: Implications for creation and reduction of intergroup bias. In L. Berkowitz (Ed.), Advances in 
experimental social psychology (Vol. 19, pp. 293-355). New York: Academic Press.

Wilder, D. A., \& Thompson, J. E. (1988).

Assimilation and contrast effects in judgments of groups. Journal of Personality and Social Psychology, 54, 62-73.

Worth, L. T., \& Mackie, D. M. (1987). Cognitive mediation of positive affect in persuasion. Social Cognition, 5, 76-94.

Paper received 22 January 2003; revised version accepted 15 June 2004.

\section{Biographical notes}

STEVEN J. STROESSNER is associate professor \& chair of psychology at Barnard College, Columbia University. His research focuses on factors that contribute to the formation and use of stereotypes.

DIANE M. MACKIE is professor of psychology at the University of California, Santa Barbara. She has two main research interests: social influence (the processes by which attitudes and behavior are changed) and intergroup relations (the processes that guide how we think and feel about and toward our own and other groups).

VENEZIA MICHALSEN is a doctoral student in the criminal justice program at The Graduate Center of CUNY. Her doctoral research focuses on formerly incarcerated women and their children. She is also the research associate at the Women's Prison Association in New York City, a nonprofit organization serving women in prison and reentering the community after prison. 